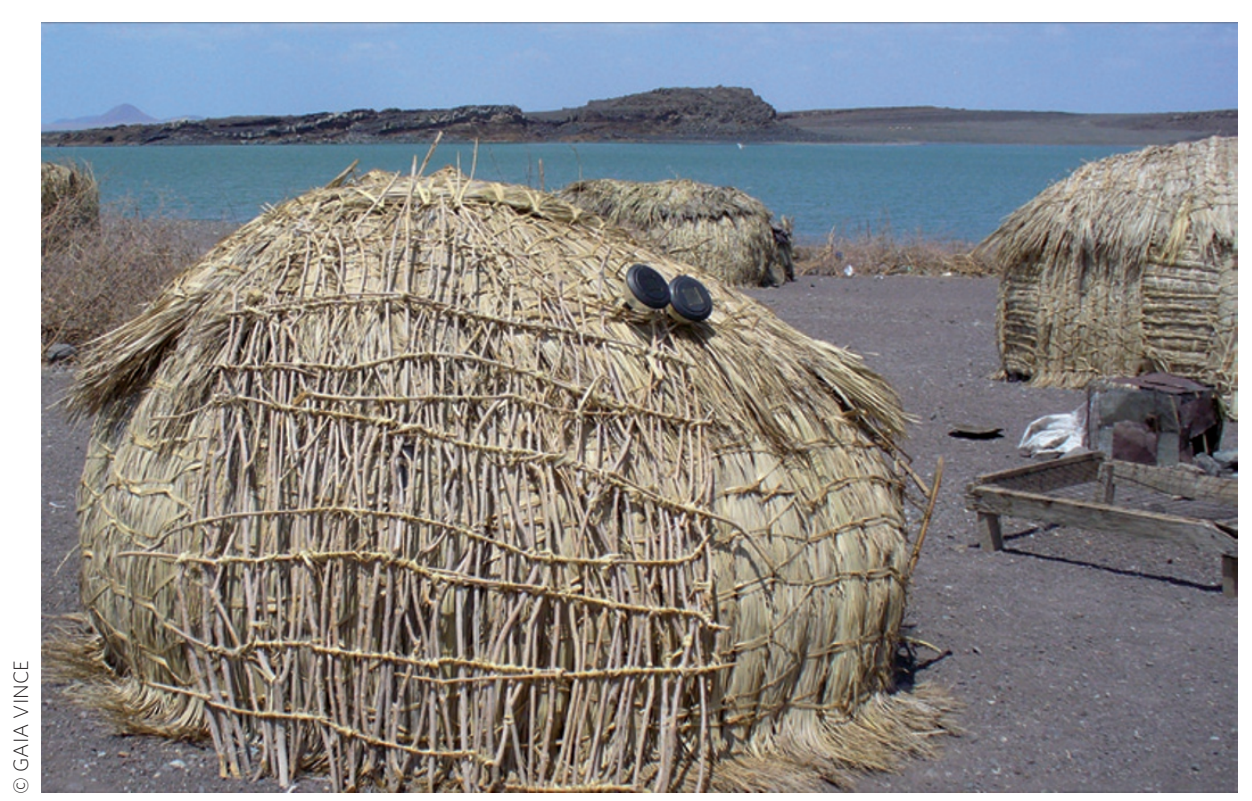

Rural options. Cheap, flexible solar power can power off-grid homes like these in Turkana, northern Kenya.

Alán Aspuru-Guzik, a chemist at Harvard University, and his team are working with IBM to find the best molecules to use in cheap solar cells. Their crowd-computing approach is similar to that used by pharmaceutical companies looking for drug candidates: they've tapped into a network of volunteer computers to screen 3.5 million organic molecules to see if any are capable of converting $10 \%$ of incoming light into electricity. So far, his team has screened 1.9 million candidates and shortlisted 1,000 molecules that could be competitive with silicon cells.

Organic photovoltaic cells already exist, but they are not very efficient, nor do they have a very long lifetime. In March, Mitsubishi Chemical Corp announced that it had produced an organic photovoltaic cell with a conversion efficiency of $8.5 \%$. Even though the best silicon-based photovoltaics boast an efficiency of $29 \%$, Aspuru-Guzik considers that an organic photovoltaic cell with just $10 \%$ efficiency would be marketable, because they would be much cheaper and could be applied to paints, lightweight plastics and fabrics.

Hannah Hoag is a science journalist based in Toronto, Canada.

Published online: 24 July 2011

\title{
SNAPSHOT
}

\section{Flying over thinning ice}

An unprecedented set of Arctic research flights is providing new sea-ice measurements and helping scientists calibrate similar data from an icemonitoring satellite.

During a six-week mission that ended in early May, research aircraft from NASA, the European Space Agency (ESA), and the Alfred Wegener Institute (AWI) for Polar and Marine Research in Bremerhaven, Germany, flew over the Arctic Ocean from sites in Alaska, Canada, Greenland and Norway. They sampled the atmosphere at various altitudes to gather meteorological data, and the aircraft towed electromagnetic sensors to measure the thickness of sea ice. These new readings will help researchers calibrate data gleaned by instruments aboard ESA's CryoSat-2 - an ice spy that has orbited Earth at an altitude just above $700 \mathrm{~km}$ since it was launched in April 2010.

Preliminary analyses suggest that the average thickness of the one-year-old sea ice in the Beaufort Sea north of Alaska and Canada this year is about $1.4 \mathrm{~m}$, which is about $20 \mathrm{~cm}$ thinner than last year's measurement, says Stefan Hendricks, a sea-ice physicist at AWI in Bremerhaven. The ice could be thinner because

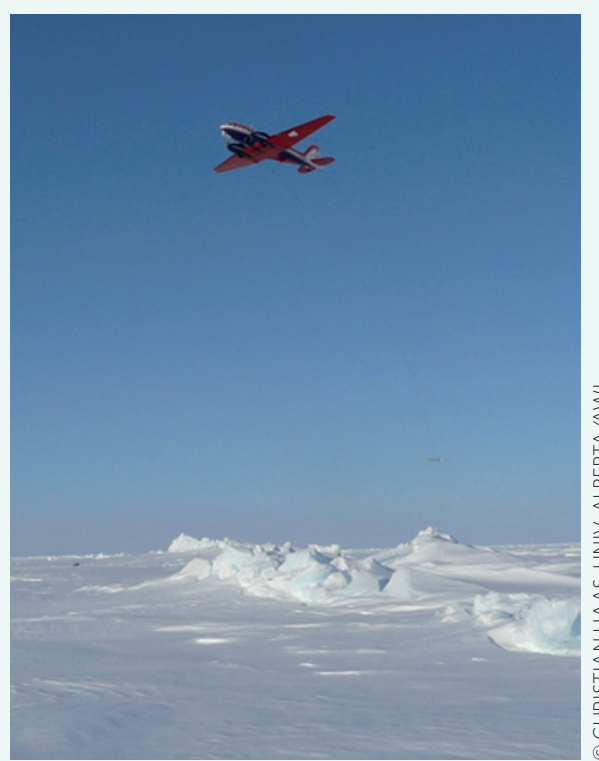

temperatures weren't as cold last winter, the freezing season was briefer or a thickerthan-normal blanket of snow insulated the underlying ice from the bitter cold air, Hendricks says. In a few weeks, Hendricks and his colleagues will announce their estimates of how low this summer's sea-ice coverage will be."I don't think this first-year ice will survive the summer," he says.

Using lasers and spectrometers on board the aircraft, the researchers assessed the number, chemical composition and size distribution of aerosols, including the particulates in ice clouds, at several altitudes over the ocean. "There have been very few observations of ice clouds in the Arctic, so we've now got data where we had none before," says Hendricks, who braved temperatures of $-30^{\circ} \mathrm{C}$ during the mission.

The team's observations will help researchers better understand chemical reactions taking place in the atmosphere over the ice-covered sea, including the depletion of tropospheric ozone over the Arctic Ocean that's been worsening in recent years, says Hendricks. As with the sea-ice measurements, the aerosol observations will help scientists calibrate data being gathered from orbit by sensors on board the CALIPSO satellite, which monitors the distribution of clouds and aerosols. These data are important for improving global and regional climate models.

SID PERKINS 